\title{
Evaluating Dancers' Participation Motives: The Use of the Greek Version of the BRSQ
}

\author{
Filippou Filippos ${ }^{1}$, Tsitskari Efi', Bebetsos Evangelos ${ }^{1}$ and Goulimaris Dimitris ${ }^{1}$ \\ 'Democritus University of Thrace, Department of Physical Education \& Sport Sciences, Komotini, Greece
}

\begin{abstract}
The study's aim was to cross-validate the "Behavioral Regulation in Sport Questionnaire" (BRSQ), of Lonsdale and his co-authors (2008) in a Greek dance context. The sample consisted of 390 dancers, 249 coming from folk dance groups and 141 from non-folkdance groups. The scale was translated into Greek using the back-translation procedure. The validity and reliability of the questionnaire were checked by performing a confirmatory factor analysis (CFA) and an internal consistency analysis using Cronbach's alpha. Descriptive statistics were calculated to broadly examine the participation motives and Independent samples t-test calculated the differences in the participants' motives according to the kind of dance they chose to participate in. The Greek version of BRSQ showed stable psychometric properties. Intrinsic motivation is highly evaluated by both traditional and modern/classic dance participants, though the participants of different types of dances statistically different evaluate some of their intrinsic and extrinsic motives of participation.
\end{abstract}

Key words: traditional dance, modern and classic dance, motivation, participants, BRSQ

\section{Introduction}

Dance, as an expression of human behavior, always fascinated people no matter of their age, sex or social tax. It has always been an integral part of both the daily and the festive life of humans (Deagon, 2008), and it has evolved into a highly cultural and recreational form of expression. Nowadays, dance is considered to be a pleasant and effective form of physical and recreational activity (Goulimaris, Mavridis, Genti, \& Rokka, 2014), and for thisreason it attracts many participants (Goulimaris, 2016). It offers both physiological and psychological benefits and, most importantly, it can be performed anywhere and at any time, without the use of any specific equipment (Judge, 2003). Researchers (Bennet \& Hackney, 2018; Kaltsatou, Kouidi, Anifanti, Douka, \& Deligiannis, 2014; Mavrovouniotis, Argiriadou, \& Papaioannou, 2010; Rokka, Mavridis, Mavridou, Kelepouris, \& Filippou, 2015; Rudolph et al., 2018), proved that asdance combines movement, social interaction and fun, it motivates participation in general, either for healthy people of all ages and for patients taking part in training programs.
Measuring and understanding consumers' motivation is of extreme importance as it helps organizations to implement any type of system aiming to improve process efficiency and efficacy, seek competitive advantage, build a brand identity and secure customer retention (Alexandris, 2012; Gonzalez, Tomas, Castillo, Duda, \& Balaguer, 2017; Mehmeti \& Halilaj, 2018; Tsitskari, Tzetzis, \& Konsoulas, 2017). Customer retention is one of the most important issues facing leisure managers, as it requires detailed knowledge of behavioral aspects of customers' decision-making process (Tsitskari et al., 2017), such as of their motives.

Literature on exercise motivation indicates that its conceptualization and measurement are not yet clear issues. Different theoretical approaches have been used and, as a result, a variety of measurement models have been proposed (Lonsdale, Hodge \& Rose, 2008; Mallet, Kawabata, Newcombe, Otero-Forero, \& Jackson, 2007; Pelletier, Fortier, Vallerand, Tuson, \& Blais, 1995). This might also be related to the heterogeneity of exercise participants and the different exercise environments worldwide. Naturally, this heterogeneity exists in

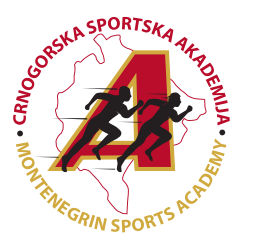

Correspondence:

F. Filippos

Democritus University of Thrace, Department of Physical Education \& Sport Sciences, Komotini, Greece

E-mail: ffilippo@phyed.duth.gr 
the evaluation of dancers' motivation, as well (Goulimaris, Filippou, \& Koupani, 2016; Filippou, Rokka, \& Mavridis, 2016). Self-determination theory (Deci \& Ryan, 2000) has been prominent in conceptualizing all types of sport motivation in terms of a qualitative continuum. The most basic distinction that its researchers proposed was that of intrinsic motivation (absence of external rewards), extrinsic motivation (external rewards), and amotivation (Deci \& Ryan, 2000).

Intrinsic motivation refers to doing an activity for the pleasure deriving from participating in it, with a complete absence of external rewards (Deci \& Ryan, 2000). Consequently, all choices taken when a person is intrinsically motivated involve a great sense of freedom. Extrinsic motivation refers to taking part in an activity for external rewards (Deci \& Ryan, 2000) and separable outcomes, to avoid punishment or satisfy an external demand (Lonsdale et al., 2008). Finally, amotivation (Ryan \& Deci, 2000), is the state of lacking an intention to act. In the sporting context, for example, amotivated athletes are likely to question the continuation of their participation (Lonsdale et al., 2008). To examine intrinsic motivation, extrinsic motivation and amotivation, following the principles of SDT in a dance participation context, a conceptually and psychometrically sound measure of behavioral regulation is essential.

Lonsdale and his cooperates (2008) offered to the research community such a scale, comprised of 36 items evaluating amotivation, intrinsic and extrinsic motivation through nine types/factors of motivation: i) One for amotivation, ii) four for intrinsic motivation (IM-General, IM to know, IM to expe-

Table 1. Sample's Demographic characteristic

\begin{tabular}{cccccc}
\hline \multicolumn{2}{c}{ Genger (\%) } & \multicolumn{2}{c}{ Age (\%) } & Dance (\%) \\
\hline Male & 22.8 & $15-18$ & 37.4 & Greek Traditional & 63.8 \\
Female & 77.2 & $19-29$ & 23.8 & Non-traditional (modern \& classical dances) & 36.2 \\
& & $30-39$ & 18.5 & & \\
& & $40-49$ & 14.4 & \\
\hline
\end{tabular}

\section{Instruments}

As the first Greek version of BRSQ (Tsitskari et al., 2015) didn't support the original's hypothesized dimensionality, the researchers decided to once again use the original scale and test it in a sample of Greek dancers. Although BRSQ was specifically designed for use with competitive sport participants (Lonsdale et al., 2008), the researchers believe that it will fit well in a less competitive environment as such of traditional and non-traditional dances' lessons.

The original scaleconsistedof 36 items, comprised in nine factors of motivation, the following: i) Amotivation, with 4 items, e.g. “...but I question why I continue”, ii) External regulation, with 4 items, e.g. “...because if I don't participate other people will not be pleased with me", iii) Introjected regulation, with 4 items, e.g. “...because I would feel guilty if I quit”, iv) Identified regulation,with 4 items, e.g. "... .because it's a good way to learn things which could be useful to me in my life", v) Integrated regulation,with 4 items, e.g. "...because it's an opportunity for me to be just who I am", vi) IM-general, with 4 items, e.g. "...because I enjoy participating in dance classes", vii) IM-Know, with 4 items, e.g. "...because I enjoy learning new things about dance", viii) IM experience Stimulation, with 4 items, e.g. "...because of the pleasure I experience when I feel rience stimulation and IM towards accomplishments) and iii) four for extrinsic motivation (Integrated, Identified, Introjected and External regulation). Each factor was evaluated through four items. The researchers named the tool "Behavioral Regulation in Sport Questionnaire (BRSQ)". The evidence that Lonsdale and his cooperates (2008) presented was supportive of the reliability and validity of the BRSQ scores. The scale has already been used in a Greek sample of young sport participants by Tsitskari, Vernadakis, Foridou and Bebetsos (2015), though the translated scale did not support the hypothesized dimensionality of the original one. After confirmatory and exploratory factor analyses, a six-factor solution resulted, that closely reproduced three of the motivational factors of the initial Australian version of BRSQ (Lonsdale et al., 2008).

The aim of the present study was to examine the factorial structure andvalidity of BRSQ in a sample of dancers participating in Greektraditionaldanceandclassicandmoderndancelessons. Moreover, the possible differences among the different dances' participants were also examined.

\section{Methods}

Participants

The sample of the study consisted of 390 dancers, recruited from ten groups offering lessons of Greek traditional dances (249 participants) and six schools offering classic and modern dance's lessons (141 participants).The samples' demographics appear in Table 1.

completely absorbed in dance", and ix) IM to accomplish, with 4 items, e.g. "...because I enjoy doing something to the best of my ability”. All answers were given in a seven-point Likert type scale ranging from $1=$ totally disagree to $7=$ totally agree.

The back-translation technique was used to translate the BRSQ scale. Two researchers translated the original BRSQ into Greek and afterwards compared the two versions. 29 out of the 36 items were translated in an almost identical way. For the remaining 7 , the two researchersdiscussed the results and concludedthat its meaning was quite identical, despite the use of different words. In each case, the translators came to an agreement to keep one of the two statements, which seemed to be the more appropriate one according to the vocabulary used, the meaning, the grammar and syntax. The Greek version was then given to two other bilingual researchers in the field of sport marketing and psychology who agreed to translate the items back into English. Neither of the two researchers had ever used the BRSQ. After the translation was accomplished, the four researchers evaluated the back-translated versions with the original Questionnaire. While some of the statements (22 out of 36) were slightly not identical to those of the original scale, the researchers agreed that their meaning was the same and decided to retain the translated Greek scale. 
To check the content validity of the questionnaire a pilot study was carried out, in which 80 traditional dancers and 40 modern dance participants. The questionnaires were filled in and the respondents didn't report any difficulty in the comprehension and the fill in of the questionnaire.

\section{Procedure}

Data were collected from October to December of 2017. Prior contact with teachers or owners/managers of traditional and modern/classic dances was made to obtain permission. The questionnaires were given to the dancers by one of the researchers before the beginning of the lesson to avoid fatigue or even sentimental responses (eg. after a good or bad day on the lesson). A total of 435 questionnaires were distributed, 397 were returned, of which, eventually, 390 were used in the study (return rate: $89.66 \%$ ).

\section{Data analysis}

Questionnaire's validity and reliability were checked by performing a confirmatory factor analysis (CFA), an internal consistency analysis using Cronbach's alpha. Independent Samples T-test was performed to examine the possible differences on participants' motives according to the type of dance.

\section{Results}

A confirmatory factor analysis was performed through LISREL 8.80 on the nine subscales of the BRSQ.The hypothesized model is presented in figure 1 where ellipses represent latent variables and rectangles represent measured variables. Figure 1 shows the path diagram for the latent and observed variables.

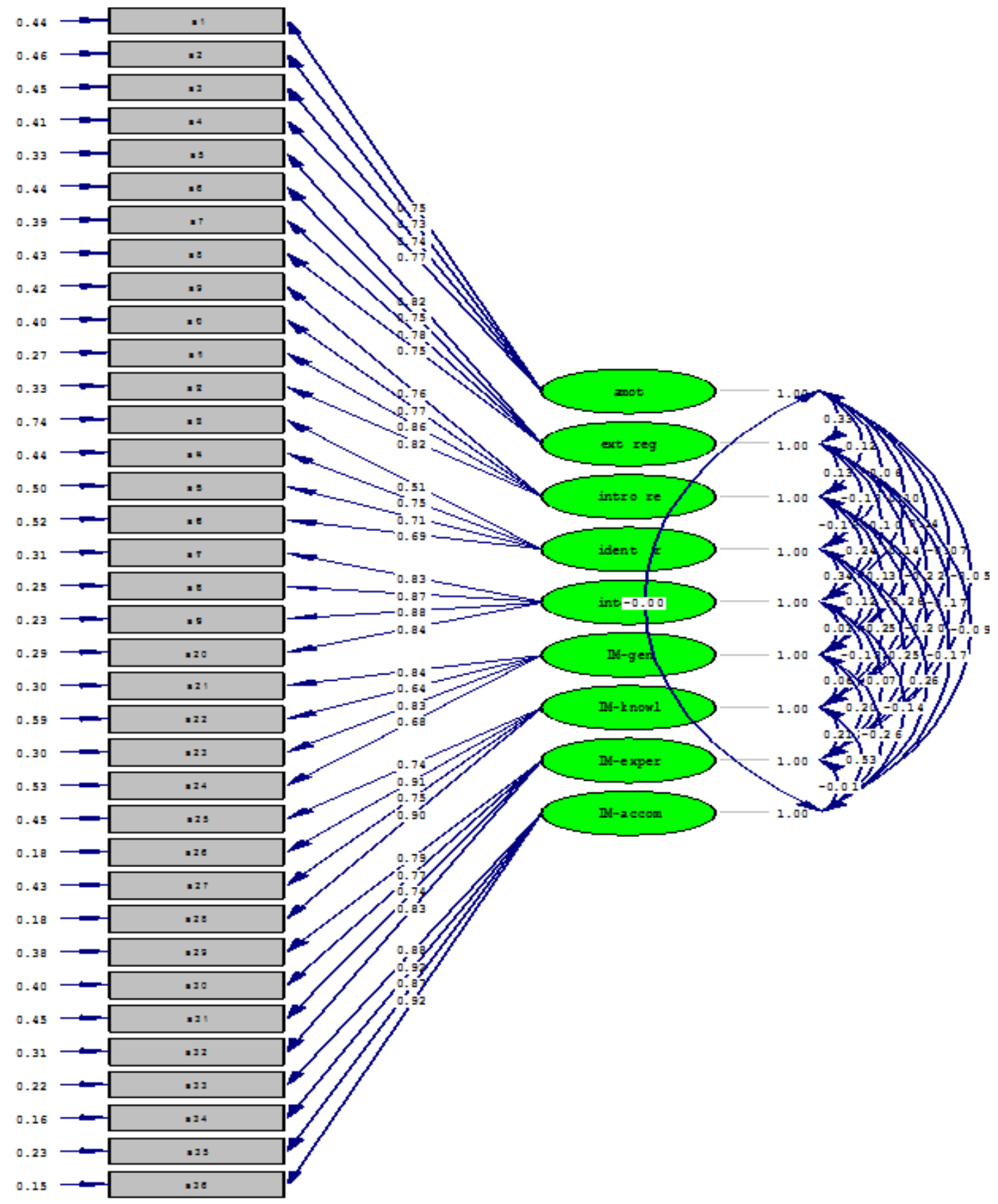

Chi-Square $=1528.31, \mathrm{df}=558, \mathrm{p}$-value $=0.00000, \mathrm{RMSE} A=0.067$

Figure 1. Path diagram of the latent on the observed variables 
The hypothesized model consists of eight latent variables, namely amotivation, external regulation, introjected regulation, identified regulation, integrated regulation, IM-general,
IM-Knowledge, IM-experience stimulation, and IM-accomplish. The observed items on the BRSQ and their corresponding questions and subscales (factors) are presented in Table 2.

Table 2. Standardized direct effects of the latent on the observed variables

\begin{tabular}{|c|c|c|c|c|c|c|c|c|c|}
\hline \multirow{2}{*}{ Items } & \multicolumn{9}{|c|}{ Factors } \\
\hline & L1 & L2 & L3 & L4 & L5 & L6 & L7 & L8 & L9 \\
\hline 1 & .75 & & & & & & & & \\
\hline 2 & .73 & & & & & & & & \\
\hline 3 & .74 & & & & & & & & \\
\hline 4 & .77 & & & & & & & & \\
\hline 5 & & .82 & & & & & & & \\
\hline 6 & & .75 & & & & & & & \\
\hline 7 & & .78 & & & & & & & \\
\hline 8 & & .75 & & & & & & & \\
\hline 9 & & & .76 & & & & & & \\
\hline 10 & & & .77 & & & & & & \\
\hline 11 & & & .86 & & & & & & \\
\hline 12 & & & .82 & & & & & & \\
\hline 13 & & & & .51 & & & & & \\
\hline 14 & & & & .75 & & & & & \\
\hline 15 & & & & .71 & & & & & \\
\hline 16 & & & & .69 & & & & & \\
\hline 17 & & & & & .83 & & & & \\
\hline 18 & & & & & .87 & & & & \\
\hline 19 & & & & & .88 & & & & \\
\hline 20 & & & & & .84 & & & & \\
\hline 21 & & & & & & .84 & & & \\
\hline 22 & & & & & & .64 & & & \\
\hline 23 & & & & & & .83 & & & \\
\hline 24 & & & & & & .68 & & & \\
\hline 25 & & & & & & & .74 & & \\
\hline 26 & & & & & & & .91 & & \\
\hline 27 & & & & & & & .75 & & \\
\hline 28 & & & & & & & .90 & & \\
\hline 29 & & & & & & & & .79 & \\
\hline 30 & & & & & & & & .77 & \\
\hline 31 & & & & & & & & .74 & \\
\hline 32 & & & & & & & & .83 & \\
\hline 33 & & & & & & & & & .88 \\
\hline 34 & & & & & & & & & .92 \\
\hline 35 & & & & & & & & & .87 \\
\hline 36 & & & & & & & & & .92 \\
\hline
\end{tabular}

Legend: L1: amotivation, L2: external regulation, L3: introjected regulation, L4: identified regulation, L5: integrated regulation, L6: IM-general, L7: IM-Knowledge, L8: IM-experience stimulation, L9: IM-accomplish

The fit indices taken into consideration were: namely $\mathrm{mi}-$ nimum discrepancy (CMIN or $\chi 2$ ), degrees of freedom (d.f.), minimum discrepancy divided by the degrees of freedom ( $\chi 2 /$ d.f.), Root Mean Square Error of Approximation (RMSEA), Standardized Root Mean Square Residual (SRMR), and incremental indices Comparative Fit Index (CFI), Normed Fit Index (NFI) (Baggozi, 1983; Banville, Desroriers, \& Genet-Vo- let, 2000; Hu \& Bentler, 1999). The results of the confirmatory factor analysis demonstrated that the hypothesized model produced a significant chi-square, $\chi 2(390,558)=1528.31, p<0.05$. The NFI and CFI were found to be 0.92 and 0.93 respectively. The RMSEA was also considered to assess the degree of fit of the model. The RMSEA value for the hypothesized model was found to be .067 and SRMR=0.044 (Table 3).

Table 3. Model Fit Indices

\begin{tabular}{cccccccc}
\hline & N & CMIN & DF & NFI & CFI & RMSEA & SRMR \\
\hline Model & 390 & 1528.31 & 558 & .92 & .93 & .067 & .044 \\
\hline
\end{tabular}




\section{Reliability analysis}

The values for alpha of Cronbach were calculated to assess the internal consistency reliabilities of the scale (0.84) and its emerged sub-scales: i) 0.84 for IM-General, ii) 0.94 for IM-Stimulation, iii) 0.90 for the IM-Know, iv) .86 for the IM-accomplish, v) 0.92 for Integrated Regulation, vi) 0.88 for Introjected Regulation, vii) .86 for External Regulation, viii) 0.76 for Identified Regulation and ix) 0.84 for Amotivation (Table 4).

\section{Evaluating the Motives whenParticipating in Dancing Activities}

As it becomes evident in Table 4, the factors "IM-general", "IM-accomplish" and "IM-knowledge" are experienced with the most considerable tension followed by "IM-experience stimulation" and "Integrated regulation". The factors "Amotivation" and "Introjected regulation" showed the lowest value.

Table 4. Means, Standard DeviationsandCronbach's a of the Intrinsic, Extrinsic and Amotivation Factors evaluated by the sample's dancers

\begin{tabular}{ccccc}
\hline & Factors & M & SD & Cronbach's a \\
\hline 1 & IM-general & 5.88 & .83 & .84 \\
2 & IM- accomplish & 5.34 & .76 & .86 \\
3 & IM-know & 5.10 & .91 & .90 \\
4 & IM- experience stimulation & 4.66 & 1.14 & .94 \\
5 & Integrated regulation & 4.50 & 1.09 & .92 \\
6 & Identified regulation & 4.39 & .74 & .76 \\
7 & External regulation & 2.72 & .91 & .86 \\
8 & Introjected regulation & 1.96 & .68 & .88 \\
9 & Amotivation & 1.75 & .68 & .84 \\
\hline
\end{tabular}

Evaluating the participants' Motives according to the type of Dance they participate in

Independent samples T-test was conducted to indicate any differences in kind of dance and participants motives. Results revealed significant statistical differences in the following subscales:

i. "IM-general" $t(388)=17.94, p<0.00$ : dancers of traditional dance $(\mathrm{M}=6.25, \mathrm{SD}=0.58)$ more positively evaluated this factor than participants of non-traditional dance $(\mathrm{M}=5.21$, $\mathrm{SD}=0.79$ ).

ii. "IM-experience stimulation" $\mathrm{t}(388)=-4.40, \mathrm{p}<0.00$ : dancers of non-traditional dances $(\mathrm{M}=4.99, \mathrm{SD}=0.76)$ more positively evaluated this motives than participants of traditional dances $(\mathrm{M}=4.47, \mathrm{SD}=1.28)$.

iii. "Integrated regulation" $\mathrm{t}(388)=-4.14, \mathrm{p}<0.00$ : dancers of non-traditional dances $(\mathrm{M}=4.79, \mathrm{SD}=0.67)$ more positively evaluated this motivational factor than dancers of traditional dance $(\mathrm{M}=4.33, \mathrm{SD}=1.24)$.

iv. "Identified regulation" $\mathrm{F}(1,389)=6.24, \mathrm{p}<0.013$ : dancers of non-traditional dances $(\mathrm{M}=4.52, \mathrm{SD}=0.69)$ more positively evaluated this factor than participants of traditional dances $(\mathrm{M}=4.31, \mathrm{SD}=0.77)$.

\section{Discussion}

The main aim of this paper was to cross-validate the "Behavior Regulation in Sport Questionnaire" (BRSQ), of Lonsdale, and his co-authors (2008) in a Greek population of different dances' participants. Moreover, the study evaluated the participants' motives and examined possible differences among traditional dancers and classic/modern dancers.

Regardingthe questionnaire's factorial and construct validity, the responses gathered from the translated scale supported the hypothesized dimensionality of the original one (Lonsdale et al., 2008), through nine types/factors of motivation: i) One for amotivation, ii) four for intrinsic motivation (IM-General, IM to know, IM to experience stimulation and IM towards accomplishments) and iii) four for extrinsic motivation (Integrated, Identified, Introjected and External regulation). According to Santos \& Lima (2017), confirmatory factor analysis is useful for the construction of theories. The results confirmed the Greek BRSQ's factorial and construct validity, in contrast with Tsitskari and her cooperates (2015) according to whomthe confirmatory factor analysis (CFA) did not provide adequate support for the factorial validity of the motivational model. This is likely to be due to the type of the activity (dance classes) combined with the rather young age of the sample, since during these ages the intense competition has not yet been developed.As far as reliability is concerned, the results have shown suitable internal consistency and temporal stability of the scale (Lonsdale et al., 2008; Stenling, Ivarsson, Lindwall, \& Gucciardi, 2018).

As for the evaluation of the motivational factors by all the participants, means showed that all dancers are highly intrinsically motivated. Members of the sample participate in dance classes for the pleasure they gain form their participation in the activity, regardless of the difficulties they encounter and the effort they make. They are interested in the knowledge that derives from their participation and what they achieve, as well as the feeling they are experiencing during their participation. And this is due to the innate need to satisfy their feelings (Kotsaki \& Papaioannou, 2005).

Finally, the kind of dance is a decisive factor in differentiating participation motives. Thus, participants in traditional dance classes are to a greater extent internally motivated in contrast to members of dance groups modern/classic classes where IM-to accomplish is more important. The results somehow confirm the current situation; dancers of classical and modern dance are keen to feeling the pressure to succeed and Greece offers very few opportunities for this to happen. Besides, having this as the sole source of income, it is quite natural for them to wish to succeed. On the other hand, traditional dancers sometimes are getting paid for their participation in performances, but this is not the only source of income. Their participation in dance groups is not actually their profession but a complementary salary. For this, they do not feel the pressure to succeed and feel more joy and pleasure from their participation. Of course, they also set goals to achieve and wish success and recognition. 
Dance teachers, as well as marketing managers of dance clubs, should frequently evaluate what intrinsically and extrinsically motivate their participants, or what causes amotivation, as the way a person views the issue of participation gradually differentiates while time passes (Tsitskari et al., 2017). Both teachers and managers of dance and cultural clubs should try to understand and offer their participants more incentives that will enhance both their intrinsic and extrinsic motivation, by enjoying their participation and developing their sentiment of accomplishment respectively.

\section{Acknowledgements}

There are no acknowledgements.

\section{Conflict of Interest}

The authors declare that there are no conflicts of interest.

Received: 27 September 2018| Accepted: 22 December 2018| Published: 01 February 2019

\section{References}

Alexandris, K. (2012). Exploring the role of motivation on the development of sport involvement. International Journal of Sport Management \& Marketing, 12(1/2), 57-72.

Baggozi, R. (1983). Issues in the application of covariance structure analysis: A further comment. Journal of Consumer Research, 9, 449-450.

Bennet, C.G., \& Hackney, M.E. (2018). Effects of line dancing on physical function and perceived limitation in older adults with self-reported mobility limitations. Disability and Rehabilitation, 40(11), 1259-1265.

Deagon, A. (2008). Folk Dance and Ethnic Identity. Dance Chronicle, 31 , 275-278.

Filippou, F., Rokka, S., \& Mavridis, G. (2016). Examining the motives for participating in dance activities using the "Physical Activity and Leisure Motivation Scale" (PALMS). Sport Science, 9(1), 42-49.

Gonzalez, L., Tomas, I., Castillo, I., Duda, J.L., \& Balaguer, I. (2017). A test of basic psychological needs theory in young soccer players: time-lagged design at the individual and team levels. Scandinavian Journal of Medicine \& Science in Sports, 27(11), 1511-1522. doi: 10.1111/sms.12778.

Goulimaris, D. (2016). Examination of the relation between the planned behavior theory and the attitudinal loyalty to recreational dance activities. Journal of Physical Education \& Sport, 16(1), 656-663.

Goulimaris, D., Mavridis, G., Genti, M., \& Rokka, S. (2014). Relationships between basic psychological needs and psychological well-being in recreational dance activities Journal of Physical Education \& Sport, 14(2), 277-284.

Goulimaris, D., Filippou, D.A., \& Koupani, A. (2016). How does the motivational climate differ among adult dancers within an educational context? Journal of Physical Education \& Sport, 16(1), 252-257.
Hu, L., \& Bentler, P.M. (1999). Cutoff criteria for fit indexes in covariance structure analysis: Conventional criteria versus new alternatives. Structural Equation Modeling, 6, 1-55.

Judge, J.O. (2003). Balance training to maintain mobility and prevent disability. American Journal of Preventive Medicine, 25(3), 150-156.

Kaltsatou, A.Ch., Kouidi, E.I., Anifanti, M.A., Douka, S.I., \& Deligiannis, A.P. (2014). Functional \& psychosocial effects of either a traditional dancing or a formal exercising training program in patients with chronic heart failure: a comparative randomized controlled study. Clinical Rehabilitation, 28(2), 128-138.

Lonsdale, C., Hodge, K., \& Rose, E.A. (2008). The Behavioral Regulation in Sport Questionnaire (BRSQ): Instrument development and initial validity evidence. Journal of Sport \& Exercise Psychology, 30(3), 323-355.

Mallet, C., Kawabata, M., Newcombbe, P., Otero-Forero, A., \& Jackson, S (2007). Sport Motivation Scale - 6 (SMS-6): A revised sic-factor sport motivation scale. Psychology of Sport \& Exercise, 8(5), 600-614.

Mavrovouniotis, F.H., Argiriadou, E.A., \& Papaioannou, C.S. (2010). Greek traditional dances and quality of old people's life. Journal of Bodywork \& Movement Therapies, 14, 209-218.

Mehmeti, I. \& Halilaj, B. (2018). How to increase motivation for physical activity among youth. Sport Mont, 16(1), 29-32. doi: 10.26773/smj.180206.

Pelletier, L.G., Fortier, M.S., Vallerand, R.J., Tuson, K.M., \& Blais, M.R. (1995) Toward a new measure of intrinsic motivation, extrinsic motivation \& amotivation in sports: The Sport Motivation Scale (SMS). Journal of Sport \& Exercise Psychology, 17(1), 35-53.

Rokka, S., Mavridis, G., Mavridou, Z., Kelepouris, A., \& Filippou, D.A. (2015). Traditional dance as recreationalactivity: Teenagers' motives participation. Sport Science, 8(2), 75-81.

Rudolph, I., Schmidt, T., Wozniak, T., Kubin, T., Ruetters, D., \& Huebner, J. (2018). Ballroom dancing as physical activity for patients with cancer: A systematic review and report of a pilot project. Journal of Cancer Research \& Clinical Oncology, 114(4), 759-770.

Ryan, R. \& Deci, E.L. (2000). Intrinsic and extrinsic motivations: classic definitions and new directions. Contemporary Educational Psychology, 25(1), 54-67.

Santos, A.A.A. \& Lima, T.H. (2017). Exploratory and confirmatory factor analysis of the Roteiro de Avaliacao da ConscienciaFonologica, a phonological awareness test. Estudos de psicologia (Campinas), 34(2), http://dx.doi. org/10.1590/1982-02752017000202223

Stenling, A., Ivarsson, A., Lindwall, M., \& Gucciardi, D.F. (2018). Exploring longitudinal measurement invariance and the continuum hypothesis in the Swedish version of the Behavioural Regulation in Sport Questionnaire (BRSQ): An exploratory structural equation modelling approach. Psychology of Sport \& Exercise, 36, 187-196.

Tsitskari, E., Tzetzis, G., \& Konsoulas, D. (2017). Perceived Service Quality and Loyalty of Fitness Centers' Customers: Segmenting Members Through Their Exercise Motives., Services Marketing Quarterly, 38(4), 253-268.

Tsitskari, E., Vernadakis, N., Foridou, A., \& Bebetsos, E. (2015). Assessing adolescents' sport participation motives: psychometricevaluation of BRSQ Motricidade, 11(1), 64-77. 